\title{
Diversity and gaps in Pennisetum glaucum subsp. monodii (Maire) Br. germplasm conserved at the ICRISAT genebank
}

\author{
H. D. Upadhyaya*, K. N. Reddy, Sube Singh, C. L. L. Gowda, \\ M. Irshad Ahmed and Vinod Kumar \\ International Crops Research Institute for the Semi-Arid Tropics (ICRISAT), Grain Legumes \\ Program, Genetic Resources, Patancheru, Andhra Pradesh 502 324, India
}

Received 21 October 2013; Revised 20 November 2013 - First published online 16 December 2013

\begin{abstract}
The International Crops Research Institute for the Semi-Arid Tropics conserves 335 accessions of Pennisetum glaucum subsp. monodii originated in 13 countries. In the present study, the collection was evaluated and assessed for diversity and geographical gaps. A wide variation was observed in the collection for total tillers per plant (16 to 609), productive tillers per plant (12 to 368), leaf length $(21.3$ to $58.8 \mathrm{~cm})$ and leaf width $(8.1$ to $33.1 \mathrm{~mm})$, indicating high fodder yield potential of the collection. The accessions of cluster 3 flowered late, grew tall with thick stems and long and broad leaves, and differed significantly from those of cluster 1 and cluster 2. The accessions of cluster 2 were found to be promising for tillering. The highly significant positive correlation $(r=0.944)$ between total and productive tillers per plant suggests that the selection for total tillers will result in selection for productive tillers. A total of 354 districts located in 86 provinces of eight countries in the primary centre of origin for pearl millet were identified as geographical gaps. The probability map generated using FloraMap in the present study matched quite closely to the origin of pearl millet, supporting the prediction of $P$. glaucum subsp. monodii occurrence in the primary centre of diversity for pearl millet. The high fodder yield potential of $P$. glaucum subsp. monodii germplasm and low intensity of collection in countries under study suggest the need for launching germplasm collection missions, exclusively for pearl millet wild relatives to fill taxonomic and geographical gaps in the collection.
\end{abstract}

Keywords: crop wild relatives; diversity; germplasm; probability; variation

\section{Introduction}

Pearl millet is a staple food grain crop and also a source of feed, fodder and construction material. It is the fifth most important cereal crop grown in over 40 countries, predominantly in Sub-Saharan Africa and Asia. In West Africa, it is one of the two main staple food crops grown by smallholder farmers in marginal agricultural

\footnotetext{
*Corresponding author. E-mail: h.upadhyaya@cgiar.org
}

environments ranging from semi-arid to arid. Crop wild relatives (CWRs) are important as potential gene contributors for breeding programmes. CWRs, particularly crop progenitors, are known for their potential to contribute beneficial traits such as pest and disease resistance, yield improvement and adaptation to the cultivated species. Pennisetum glaucum subsp. monodii (Maire) Brunken, the progenitor of cultivated pearl millet belonging to the primary gene pool, is mainly found as a weed by the roadside and along farmers' fields in the Sahel region of Africa (Brunken et al., 1977). It is an annual erect culm mostly distributed 
in Africa. Mariac et al. (2006) reported wild populations to be an interesting source of new alleles and new allele combinations, which could be useful for broadening the genetic base of cultivated pearl millet. Several reports have indicated the usefulness of $P$. glaucum subsp. monodii in pearl millet improvement. In their evaluation of disease resistance in the primary and tertiary Pennisetum gene pools, Wilson and Hanna (1992) noted that resistance was more commonly found and more effective in wild species than in landraces. Hanna (1987) reported P. glaucum subsp. monodii to be an excellent source of genetic diversity for new cytoplasms, stable cytoplasmic sterility, fertility restoration, hybrid vigour and pest resistance. Rai and Rao (1996) identified restorers for $\mathrm{A}_{5}$ cytoplasm in six accessions of P. glaucum subsp. monodii germplasm. Despite their importance in crop improvement, genebanks worldwide are conserving only a fraction of the total genetic variability that exists in CWRs, and only a small proportion of conserved accessions have been characterized and utilized in crop improvement.

Being the world's largest repository for the germplasm of its mandate crops and their wild relatives, the ICRISAT genebank has assembled a total of 22,211 pearl millet germplasm accessions including 750 accessions of 24 species of Pennisetum from 50 countries. The collection of wild Pennisetum includes 335 accessions of P. glaucum subsp. monodii from 13 countries. The critical assessment of diversity in the existing collection, identification of geographical gaps and launching of germplasm collection missions in the unexplored and underexplored areas are necessary to increase the variability in the collection. Therefore, the present study aimed to characterize and evaluate $P$. glaucum subsp. monodii germplasm assembled at the ICRISAT genebank, assessing diversity and identifying geographical gaps in the collection for possible exploration in future to increase the variability and enhance its utilization in pearl millet improvement.

\section{Materials and methods}

The present study included 335 accessions of P. glaucum subsp. monodii assembled at the ICRISAT genebank, Patancheru, India, originated in 13 countries (Table 1 and Fig. 1). A total of 333 accessions, where seed quantity was sufficient, were characterized during the 2011 rainy season under field conditions [alfisol-Patancheru Soil Series (Udic Rhodustolf)] at ICRISAT, Patancheru $\left(18^{\circ} \mathrm{N}\right.$, $79^{\circ} \mathrm{E}, 545 \mathrm{~m}$ above sea level, and $600 \mathrm{~km}$ away from sea), Andhra Pradesh, India. The experiment was laid out in an alpha design with two replications. Three cultivars, IP 4021 - an early-flowering landrace, IP 17862 - a released cultivar developed at ICRISAT, and IP 22269 - a high-tillering gene pool developed at the ICRISAT genebank, were used as controls. The seeds were germinated in small paper cups filled with red soil mix, and 15-d-old seedlings of each accession were transplanted in a single row of $8 \mathrm{~m}$ length with a row-to-row distance of $75 \mathrm{~cm}$ and a plant-to-plant distance of $50 \mathrm{~cm}$ within the row. The crop received $150 \mathrm{~kg} \mathrm{ha}^{-1}$ Di-Ammonium Phosphate (DAP) as basal dose and $100 \mathrm{~kg} / \mathrm{ha}$ of urea as top dressing $20 \mathrm{~d}$ after sowing. Life-saving irrigation was provided. The crop was protected from pests and diseases and weeds. Observations

Table 1. Summary of Pennisetum glaucum subsp. monodii germplasm assembled at the ICRISAT genebank, Patancheru, India

\begin{tabular}{|c|c|c|c|c|c|c|}
\hline \multirow[b]{2}{*}{ Country } & \multicolumn{3}{|c|}{ Collections } & \multirow[b]{2}{*}{ Introductions } & \multirow[b]{2}{*}{ Total } & \multirow[b]{2}{*}{$\begin{array}{l}\text { Accessions having } \\
\text { latitude information }\end{array}$} \\
\hline & $\begin{array}{l}\text { Mission } \\
\text { code }\end{array}$ & Year & $\begin{array}{c}\text { No. of } \\
\text { accessions }\end{array}$ & & & \\
\hline Burkina Faso & & & & 6 & 6 & 6 \\
\hline Cameroon & 128 & 1985 & 3 & & 3 & 3 \\
\hline England & & & & 1 & 1 & \\
\hline India & 84 & 1981 & 2 & & 2 & 2 \\
\hline \multirow[t]{2}{*}{ Mali } & 135 & 1986 & 24 & 16 & 87 & 87 \\
\hline & 175 & 1989 & 47 & & & \\
\hline Mauritania & 145 & 1987 & 14 & 10 & 24 & 24 \\
\hline Niger & & & & 137 & 137 & 137 \\
\hline Nigeria & 162 & 1988 & 7 & & 7 & 7 \\
\hline Sudan & 163 & 1988 & 15 & 1 & 16 & 16 \\
\hline Senegal & 146 & 1987 & 9 & 3 & 12 & 12 \\
\hline Chad & 161 & 1988 & 30 & 3 & 33 & 33 \\
\hline United States of America & & & & 5 & 5 & \\
\hline Zimbabwe & 152 & 1988 & 2 & & 2 & \\
\hline Total & & & 153 & 182 & 335 & 327 \\
\hline
\end{tabular}




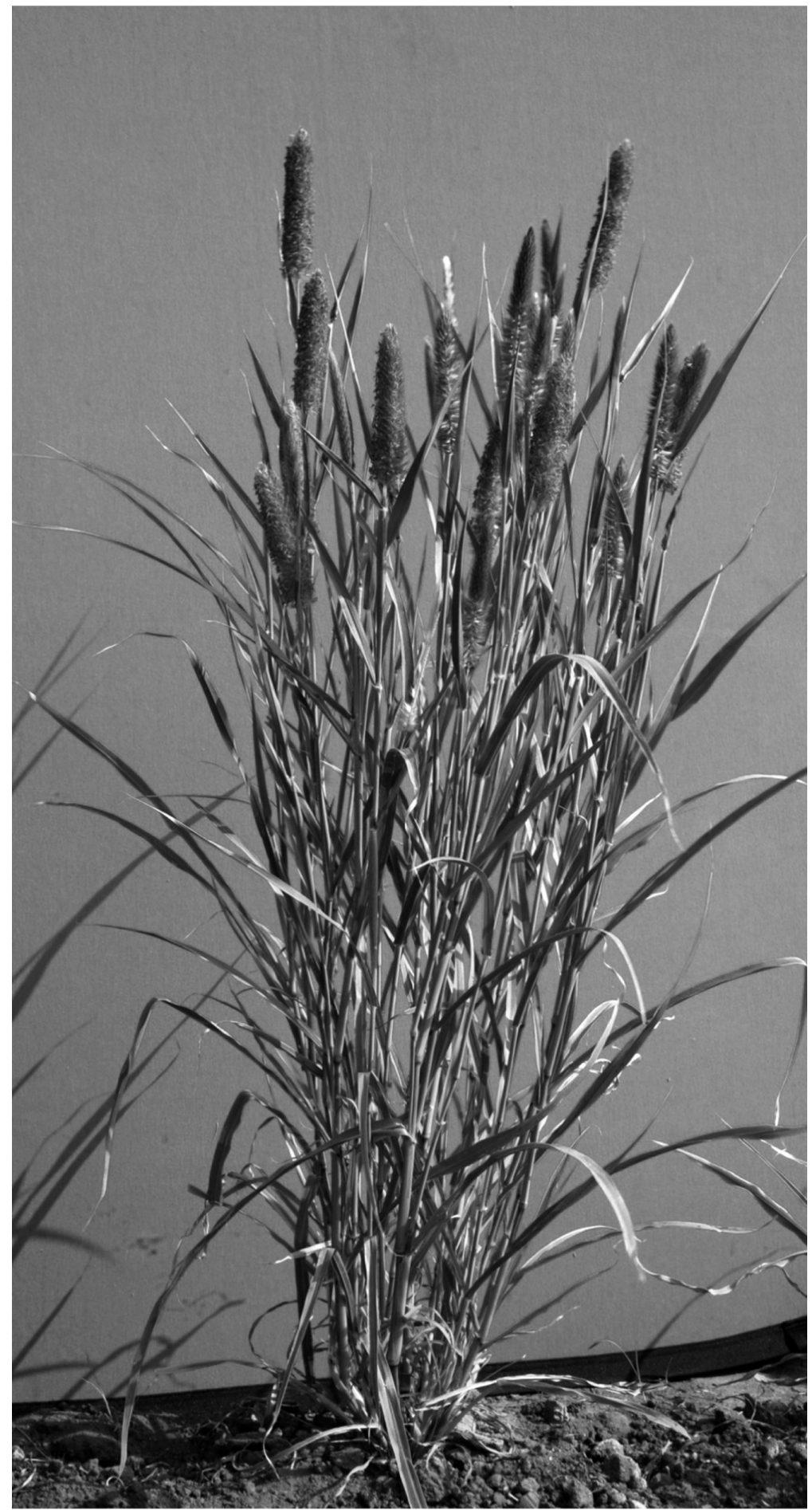

Fig. 1. Plant of Pennisetum glaucum subsp. monodii.

were recorded on ten quantitative traits and nine qualitative traits. The qualitative traits were growth habit, stem colour, leaf blade pubescence, leaf shape and colour, panicle shape and density, bristle length and green fodder yield potential on plot basis. Panicle density was scored on a $1-9$ scale $(1=$ loose and $9=$ highly compact). Bristle length was scored on a 1-9 scale. A score $<4$ indicates bristles below seed level, a score of 4-6 indicates bristles about $0-2 \mathrm{~cm}$ above seed level, and a score $>6$ indicates bristles about $2-4 \mathrm{~cm}$ above 
seed level. Green fodder yield potential was scored on a 1-9 scale $(1=$ poor fodder yielder and $9=$ best fodder yielder) by considering plant height, tillering and leafiness. Stigma emergence in 50\% of the plants in a plot was recorded as days to $50 \%$ flowering. Five representative plants were selected in each plot to record observations on plant height $(\mathrm{cm})$, total and productive tillers (no.) per plant, stem thickness $(\mathrm{mm})$, leaf length $(\mathrm{cm})$, leaf width $(\mathrm{mm})$, panicle length $(\mathrm{cm})$, panicle thickness $(\mathrm{mm})$ and panicle exsertion (cm) (IBPGR and ICRISAT, 1993).

The residual maximum likelihood (REML) method was used to analyse data obtained for the ten quantitative traits using Genstat 14 release (http:/www.vsni. co.uk) considering genotypes as random (Patterson and Thompson, 1971). Variance components due to genotype $\left(\delta^{2} g\right)$ and its standard errors (SE) were estimated. A cluster analysis was carried out by subjecting distance matrix to the hierarchical cluster algorithm of Ward (1963) at an $R^{2}$ (squared multiple correlation value) of 0.75 by means of SAS 9.1.3 (SAS Institute, 2010). This method optimizes an objective function because it minimizes the sum of squares within groups and maximizes the sum of squares between groups. Means, ranges and variances were calculated for the ten quantitative traits of each cluster and for the entire collection. The means for different traits were compared using the Newman-Keuls procedure (Newman, 1939; Keuls, 1952). The homogeneity of variances was tested using Levene's test (Levene, 1960). The Shannon-Weaver diversity index $\left(H^{\prime}\right)$ (Shannon and Weaver, 1949) was used to measure and compare phenotypic diversity for each trait. The diversity index was estimated for the ten quantitative traits across all the accessions. Phenotypic correlations were estimated among all the quantitative characteristics and tested for their significance (Snedecor and Cochran, 1980). Phenotypic proportions were estimated for qualitative traits.

Accession information for the precise location of collection sites and corresponding geographical coordinates was updated using Microsoft Encarta $^{\circledR}$, an electronic atlas (MS Encarta Interactive World Atlas, 2000). Accessions from Burkina Faso (6), Cameroon (3), India (2), Mali (87), Mauritania (24), Niger (137), Nigeria (7), Sudan (16), Senegal (12) and Chad (33) have the information on latitude and longitude. Accessions from Burkina Faso (6), Cameroon (3), India (2) and Nigeria (7) are fewer in number and therefore not considered for identifying gaps in collections from these countries. The final set of 307 accessions from six countries was used to identify gaps in the collections from individual countries.

FloraMap, a Geographical Information System (GIS) tool developed at Centro Internacional de Agricultura Tropical
(Jones and Gladkov, 1999), was used to predict the probable areas of $P$. glaucum subsp. monodii occurrence. The basic input in the FloraMap software is the geographical coordinates (latitude and longitude) of the sampling site with a unique identifier (accession number). The FloraMap system is based on the calculation of the probability that a climate record belongs to a multivariate normal distribution described by the climates at the collection points of a calibration set of organisms. With its user-friendly interface linked to agroclimatic database, we can create maps showing the most likely distribution of any particular species in nature. FloraMap assigns climate data (monthly rainfall, minimum and maximum temperature, and diurnal range in temperature) to each of the collection sites from the database provided along with the tool. Principal component (PC) analysis is used to reduce the dimensionality of this 36-dimensional dataset (set of 12 of the three variables) for each collection site and selected first five components, which contribute to the maximum variation of the climatic characteristics. Also, these components are uncorrelated or orthogonal. A probability density function is calculated based on these few uncorrelated variables to determine the probability of finding a location for the population. While working on the passport dataset, weights of 1.00 for rainfall, 1.01 for temperature and 0.99 for diurnal temperature were allocated and an exponential transformation with a power of 0.5 was applied to the monthly rainfall data. More than $94.2 \%$ of the total variation was explained by the first five PCs. A probability map was generated, and probabilities greater than 50\% were considered for germplasm collection. While estimating the probability of $P$. glaucum subsp. monodii occurrence, multiple accessions with the same coordinates were treated as a single collection site. Collection sites or sampled sites were overlaid on the probability image, and districts with high-probability $(>50 \%)$ areas, where no collection or few collections have been made, were identified as gaps. All the districts identified as geographical gaps are given in the map (shaded area) along with the sites of past collections.

\section{Results}

\section{Germplasm assembly}

The analysis of the passport data of $P$. glaucum subsp. monodii germplasm assembled at the ICRISAT genebank revealed a total of 335 accessions in the collection from 13 countries, mostly from the primary centre of origin for pearl millet (Table 1 and Fig. 1). Initially, ICRISAT introduced 182 accessions from nine countries. Donors of $P$. glaucum subsp. monodii germplasm include the Institut Français de Recherche Scientifique pour le 
Développement en Coopération (ORSTOM, meanwhile called 'Institut de Recherche pour le Développement'), Paris, France (146); Bioversity International (formerly IPGRI and IBPGR) (30); University of Georgia, USA (5); and Rothamsted, UK (1). ICRISAT in collaboration with its partners in different countries had launched 216 germplasm collection missions mainly for its mandate crops germplasm including pearl millet. During these collection missions, samples of wild relatives were also collected. A total of 153 accessions of P. glaucum subsp. monodii were collected during ten collection missions launched in nine countries during 1981-1989. Most of the collection missions launched by ORSTOM, France, were exclusively for the wild relatives of pearl millet. ICRISAT and its partners had launched two collection missions in Mali for pearl millet and also collected 71 accessions of $P$. glaucum subsp. monodii. The available georeference data indicated that the P. glaucum subsp. monodii collection assembled is from a latitude range of $11.30^{\circ} \mathrm{N}$ in Nigeria to $19.97^{\circ} \mathrm{N}$ in Mali.

\section{Diversity in the collection}

\section{Qualitative traits}

Two growth habits (erect and spreading) were found in the collection. More than $90 \%$ of the P. glaucum subsp. monodii accessions had spreading growth habit. Six stem colours (green, green + purple, green + red, purple, purple + green, and red) were found in the collection. Purple stem colour was predominant (54\%), followed by green stem colour (43\%). About $88 \%$ of the accessions had pubescence on leaf blades and other accessions did not produce pubescence on leaf blades.
Linear leaves were produced by $52 \%$ of the accessions and lanceolate leaves by $48 \%$. Green leaves were produced by $72 \%$ of the accessions, dark green leaves by $19 \%$, and light green leaves by $9 \%$. Only three panicle shapes (cylindrical, conical and candle) were found in the collection (Fig. S1, available online). Accessions producing candle-shaped panicles were predominant (88\%) in the collection. Scoring on a 1-9 scale for panicle density indicated that all the accessions produced loose panicles (score $<5$ ). Medium long bristles were produced by $87 \%$ of the accessions (score $4-6,0-2 \mathrm{~cm}$ above seed level). A score of 6 was obtained by $19.5 \%$ of the accessions (bristle length $2-4 \mathrm{~cm}$ above seed level), indicating $P$. glaucum subsp. monodii to be a good source of resistance for seed damage due to birds. A score of 1-3 was obtained by $10.8 \%$ of the accessions (bristles below seed level). For green fodder yield potential, 67 accessions scored 6 and 22 accessions scored 7.

\section{Quantitative traits}

REML analysis. The REML analysis indicated a highly significant genotypic variance $\left(\delta^{2} g\right)$ for all the traits under study, indicating a considerable variation in the collection for these traits (Table 2).

Cluster analysis. The cluster analysis resulted in three clusters. Clustering revealed no effect of geographical origin on the agronomic performance of accessions (Table 2). Cluster 1 was found to be largest, consisting 125 accessions representing 11 countries. Cluster 2 consisting 107 accessions represented eight countries and cluster 3 consisting 104 accessions (including three controls) represented 12 countries.

Variances. The homogeneity of variances of the three clusters was tested for all the ten quantitative traits using

Table 2. Variances and Shannon-Weaver diversity index $\left(H^{\prime}\right)$ values for various traits in different clusters of Pennisetum glaucum subsp. monodii germplasm conserved at the ICRISAT genebank, Patancheru, India

\begin{tabular}{lrrrrrrr}
\hline & \multicolumn{7}{c}{ Variance } \\
\cline { 2 - 5 } & $\begin{array}{c}\text { Cluster 1 } \\
\text { Trait }\end{array}$ & $\begin{array}{c}\text { Cluster 2 } \\
(107)\end{array}$ & $\begin{array}{c}\text { Cluster 3 } \\
(104)\end{array}$ & F value & Probability & $\delta^{2} g^{\text {a }}$ & $H^{\prime}$ index \\
\hline Days to 50\% flowering & 7.4 & 29.9 & 15.1 & 12.1 & $<0.0001$ & 25.90 & 0.578 \\
Plant height (cm) & 149.3 & 155.7 & 242.9 & 3.0 & 0.0494 & 651.40 & 0.626 \\
Total tillers per plant (no.) & 1429.5 & 11077.6 & 954.4 & 7.7 & 0.006 & 5206.00 & 0.468 \\
Productive tillers per plant (no.) & 552.3 & 2796.3 & 382.8 & 6.4 & 0.0018 & 1610.21 & 0.499 \\
Stem thickness (mm) & 0.2 & 0.2 & 0.9 & 9.6 & $<0.001$ & 1.15 & 0.592 \\
Leaf length (cm) & 23.8 & 13.0 & 27.6 & 5.6 & 0.0042 & 77.72 & 0.626 \\
Leaf width (mm) & 4.6 & 2.4 & 12.1 & 1.1 & $<0.0001$ & 22.16 & 0.610 \\
Panicle length (cm) & 2.1 & 1.3 & 3.1 & 4.2 & 0.0165 & 5.63 & 0.620 \\
Panicle thickness (mm) & 1.4 & 1.8 & 2.1 & 1.1 & 0.3248 & 2.79 & 0.614 \\
Panicle exsertion (cm) & 0.3 & 0.6 & 0.6 & 11.3 & $<0.0001$ & 1.44 & 0.621 \\
Mean & & & & & & & 0.585 \\
SE & & & & & & & 0.018 \\
\hline
\end{tabular}

${ }^{\mathrm{a}} \delta^{2} g$ were significant at $P=0.001$ for all the traits. 
Table 3. Ranges and means for various traits in different clusters of Pennisetum glaucum subsp. monodii germplasm conserved at the ICRISAT genebank, Patancheru, India

\begin{tabular}{lcccc}
\hline & & \multicolumn{3}{c}{ Range (mean*) } \\
\cline { 3 - 5 } & $\begin{array}{c}\text { Entire } \\
\text { collection }\end{array}$ & $\begin{array}{c}\text { Cluster } 1 \\
(125)\end{array}$ & $\begin{array}{c}\text { Cluster } 2 \\
(107)\end{array}$ & $\begin{array}{c}\text { Cluster } 3 \\
(104)\end{array}$ \\
\hline Trait & $66-92(72.9)$ & $66-79(71.7 \mathrm{~b})$ & $66-92(71.8 \mathrm{~b})$ & $67-83(75.3 \mathrm{a})$ \\
Days to 50\% flowering & $80-199(139.0)$ & $110-168(139.8 \mathrm{~b})$ & $80-145(114.9 \mathrm{c})$ & $102-199(62.1 \mathrm{a})$ \\
Plant height (cm) & $16-609(102.8)$ & $41-220(96.7 \mathrm{~b})$ & $44-609(127.8 \mathrm{a})$ & $16-202(84.4 \mathrm{~b})$ \\
Total tillers per plant (no.) & $12-368(65.8)$ & $29-145(63.7 \mathrm{~b})$ & $29-368(79.7 \mathrm{a})$ & $12-120(54.2 \mathrm{c})$ \\
Productive tillers per plant (no.) & $3-11(5.2)$ & $4-7(5.1 \mathrm{~b})$ & $3-6(4.4 \mathrm{c})$ & $4-11(6.1 \mathrm{a})$ \\
Stem thickness (mm) & $21-59(40.4)$ & $32-56(41 \mathrm{~b})$ & $21-38(31.9 \mathrm{c})$ & $32-59(48.5 \mathrm{a})$ \\
Leaf length $(\mathrm{cm})$ & $8-33(16.5)$ & $12-23(16.2 \mathrm{~b})$ & $8-17(12.4 \mathrm{c})$ & $14-33(21.0 \mathrm{a})$ \\
Leaf width $(\mathrm{mm})$ & $9-23(13.8)$ & $11-18(13.7 \mathrm{~b})$ & $9-15(12.0 \mathrm{c})$ & $12-23(15.7 \mathrm{a})$ \\
Panicle length $(\mathrm{cm})$ & $9-20(12.3)$ & $9-14(12.1 \mathrm{~b})$ & $9-15(12.1 \mathrm{~b})$ & $10-20(12.7 \mathrm{a})$ \\
Panicle thickness $(\mathrm{mm})$ & $4-8(5.5)$ & $4-6(5.2 \mathrm{~b})$ & $4-7(5.4 \mathrm{~b})$ & $4-8(5.9 \mathrm{a})$ \\
Panicle exsertion $(\mathrm{cm})$ & & & &
\end{tabular}

* Means followed by different letters are significant at $P=0.05$.

Levene's test (Levene, 1960). The variances were heterogeneous for all the traits under study, except for panicle thickness (Table 2).

Phenotypic diversity. $H^{\prime}$ was calculated to assess phenotypic diversity in the collection for all the traits under study (Table 2) (Shannon and Weaver, 1949). A low $H^{\prime}$ indicates extremely unbalanced frequency classes for an individual trait and lack of genetic diversity in the collection. In the entire collection, diversity index $\left(H^{\prime}\right)$ ranged from $0.468 \pm 0.018$ for total tillers per plant to $0.626 \pm 0.018$ for plant height and leaf length. Overall mean diversity was $0.585 \pm 0.018$.

Ranges and means. The range and mean data pertaining to various traits of $P$. glaucum subsp. monodii collection are presented in Table 3. A wide variation was observed for different traits under study. Days to $50 \%$ flowering ranged from 66 to $92 \mathrm{~d}$ with a mean of $72.9 \mathrm{~d}$, and plant height ranged from 80 to $199 \mathrm{~cm}$ with a mean of $139.0 \mathrm{~cm}$. Total and productive tillers per plant, which contribute to fodder yield, varied widely and ranged from 16 to 609 and 12 to 368 , respectively. Stem thickness varied from 3 to $11 \mathrm{~mm}$ with a mean of $5.2 \mathrm{~mm}$. Leaf length and width, which reflect fodder yield potential of accessions, ranged from 21 to $59 \mathrm{~cm}$ and 8 to $33 \mathrm{~mm}$, respectively. The panicles of $P$. glaucum subsp. monodii were small, and their length varied from 9 to $23 \mathrm{~cm}$ with a mean panicle length of $13.8 \mathrm{~cm}$. Only eight accessions (IP 21612, IP 22065, IP 21668, IP 21672, IP 21626, IP 21693, IP 21673 and IP 21563) flowered earlier than the best control IP 4021, which flowered in $67 \mathrm{~d}$. None of the accessions grew taller and produced thicker stems and longer leaves than the best control IP 22269, which grew to a height of $199 \mathrm{~cm}$ and produced thick stems $(10.6 \mathrm{~mm})$ and long leaves $(58.8 \mathrm{~cm})$. All the accessions produced more total as well as productive tillers than IP 22269, which produced 27 total tillers and 18 productive tillers. IP 21642 (609), IP 21638 (592), IP 21637 (554) and IP 22008 (512) produced more than 500 total tillers. IP 21642 (368), IP 21638 (299), IP 21632 (211), IP 21637 (210) and IP 21990 (205) produced more than 200 productive tillers. The Newman-Keuls test of significance for mean values indicated significant differences among the clusters for all the traits. Cluster 3 differed significantly from cluster 1 and cluster 2 for all the traits, except for total tillers per plant. The accessions of cluster 3 flowered late, grew taller with thicker stems, and had longer and broader leaves and highly exserted long and thick panicles than those of the other clusters. The accessions of cluster 2 were found to be highly diverse and the best source of both total and productive tillers per plant with thin stems, smaller leaves and smaller panicles.

Correlations. Phenotypic correlations were significant for all the trait combinations, except for total tillers with stem thickness, total and productive tillers with panicle thickness, and panicle exsertion and leaf length with panicle exsertion. However, correlations of total and productive tillers with plant height, leaf length, leaf width and panicle length were negative (Table 4).

\section{Intensity of collection}

Since multiple accessions with the same coordinates were treated as a single collection site, the number of actual geographical sites within an area of $18 \mathrm{~km}^{2}$ (resolution of climate data) in the present study is lesser than the number of sampled sites. Accessions having georeference data represent a total of 254 geographical sites of P. glaucum subsp. monodii collection in Burkina Faso (4), Cameroon (2), Chad (19), Mali (65), Mauritania (16), Niger (119), Nigeria (4), Senegal (12) and Sudan (13). The average number of samples per collection site 
Table 4. Correlation coefficients for various traits of Pennisetum glaucum subsp. monodii germplasm conserved at the ICRISAT genebank, Patancheru, India

\begin{tabular}{|c|c|c|c|c|c|c|c|c|c|}
\hline Trait & DFL & PHT & TT & PT & STMTH & LL & LW & PL & PTHICK \\
\hline PHT & $0.388^{* *}$ & & & & & & & & \\
\hline TT & $0.205^{* *}$ & $-0.122 *$ & & & & & & & \\
\hline PT & $0.127^{* *}$ & $-0.142^{* *}$ & $0.944^{* *}$ & & & & & & \\
\hline STMTH & $0.411^{* *}$ & $0.793^{* *}$ & -0.096 & $-0.126^{* *}$ & & & & & \\
\hline LL & $0.298^{* *}$ & $0.848^{* *}$ & $-0.223^{* *}$ & $-0.226^{* *}$ & $0.730^{* *}$ & & & & \\
\hline LW & $0.396^{* *}$ & $0.810^{* *}$ & $-0.202^{* *}$ & $-0.236^{* *}$ & $0.760^{* *}$ & $0.884^{* *}$ & & & \\
\hline PL & $0.156^{* *}$ & $0.658^{* *}$ & $-0.333^{* *}$ & $-0.336^{* *}$ & $0.593^{* *}$ & $0.672^{* *}$ & $0.671^{* *}$ & & \\
\hline PTHICK & $0.141^{* *}$ & $0.201^{* *}$ & -0.078 & -0.087 & $0.334^{* *}$ & $0.201^{* *}$ & $0.244^{* *}$ & $0.342 * *$ & \\
\hline EXN & $0.193^{* *}$ & $0.156^{* *}$ & -0.031 & -0.024 & $0.176^{* *}$ & 0.078 & $0.145^{* *}$ & $0.325^{* *}$ & $0.245^{* *}$ \\
\hline
\end{tabular}

DFL, days to $50 \%$ flowering; PHT, plant height; TT, total tillers per plant; PT, productive tillers per plant; STMTH, stem thickness; LL, leaf length; LW, leaf width; PL, panicle length; PTHICK, panicle thickness; EXN, panicle exsertion.

*Significant at $P=0.05$.

**Significant at $P=0.01$.

$\left(18 \mathrm{~km}^{2}\right)$ was 1.3 in the entire collection and 1.0 in Burkina Faso, Cameroon and Senegal, 1.1 in Niger, 1.2 in Sudan, 1.3 in Mali, 1.5 in Mauritania, 1.7 in Chad and 1.8 in Nigeria, indicating the low intensity of P. glaucum subsp. monodii collection in these countries.

\section{Geographical gaps}

Geographical gaps were mostly found in countries covering the primary centre of origin for pearl millet. High-probability $(>50 \%)$ area with less and/or no collection sites indicated 354 districts located in 86 provinces of eight countries in the primary centre of origin as geographical gaps (Fig. 2, Table S1, available online). Mali with 158 districts in 35 provinces was identified as the major gap. Sixty-seven districts of 14 provinces in Burkina Faso; 59 districts of seven provinces in Nigeria; 24 districts of eight provinces in Mauritania; 15 districts of four provinces in Senegal; 14 districts of seven provinces in Sudan; 12 districts of six provinces in Niger; and five districts of five provinces in Chad were identified as the geographical gaps in the world collection of P. glaucum subsp. monodii germplasm at the ICRISAT genebank. Among the provinces, Yatenga province in Burkina Faso with a maximum of 17 districts, followed by Jigawa and Sokoto provinces in Nigeria with 15 and 16 districts, respectively, was found to be the important gap.

Provinces such as Nara (20) and Nioro (10) in Mali; Maradi (16), Tahoua (37), Tillabery (19) and Zinder (15) in Niger; and Darfur (16) in Sudan are well represented in the existing collection. However, a few districts were identified in these provinces as gaps (Table S1, available online). The low intensity of collection in the gaps identified in the present study suggests that the provinces such as Oudalan in Burkina Faso; Borkou-Ennedi Tibesti in Chad; Bandiagara, Bourem, Diema, Gao,
Gourma-Rharous, Kolokani, Koro and Tombouctou in Mali; Assaba, Brakna, Gorgol, Hodh ech, Tagant and Trarza in Mauritania; Diffa and Dosso in Niger; Bauchi, Borno, Jigawa, Katsina, Kebbi, Sokoto and Yobe in Nigeria; and Matam in Senegal were explored partly in the past.

\section{Discussion}

The wide variation observed, particularly for total (16-609) and productive (12-368) tillers per plant and leaf length $(21-59 \mathrm{~cm})$ and width $(8-33 \mathrm{~mm})$, in the P. glaucum subsp. monodii collection at the ICRISAT genebank, is very useful for pearl millet improvement. When compared with cultivated pearl millet, $P$. glaucum subsp. monodii produced more tillers and transfer of this trait into a cultivated elite background may be very useful for increasing the fodder productivity in pearl millet. As P. glaucum subsp. monodii readily crosses with the cultivated pearl millet, accessions such as IP 21642, IP 21638, IP 21637 and IP 22008, which produced more total tillers ( $>500$ tillers), and IP 21642, IP 21638, IP 21632, IP 21637 and IP 21990, which produced more productive tillers (>200), may be exploited for increased fodder as well as grain yield (Hanna, 1987). The accessions of cluster 3, which flowered late, grew tall and produced thick stems and long and broad leaves, are very useful for increasing fodder productivity in pearl millet. Because of thin stems compared with cultivated pearl millet, leafiness and high tillering, $P$. glaucum subsp. monodii forms a good source of palatable fodder. It can be used as green fodder at earhead emergence, but it can also be made into silage and hay for dairy cattle. The highly significant positive correlation $(r=0.944)$ between total and productive 


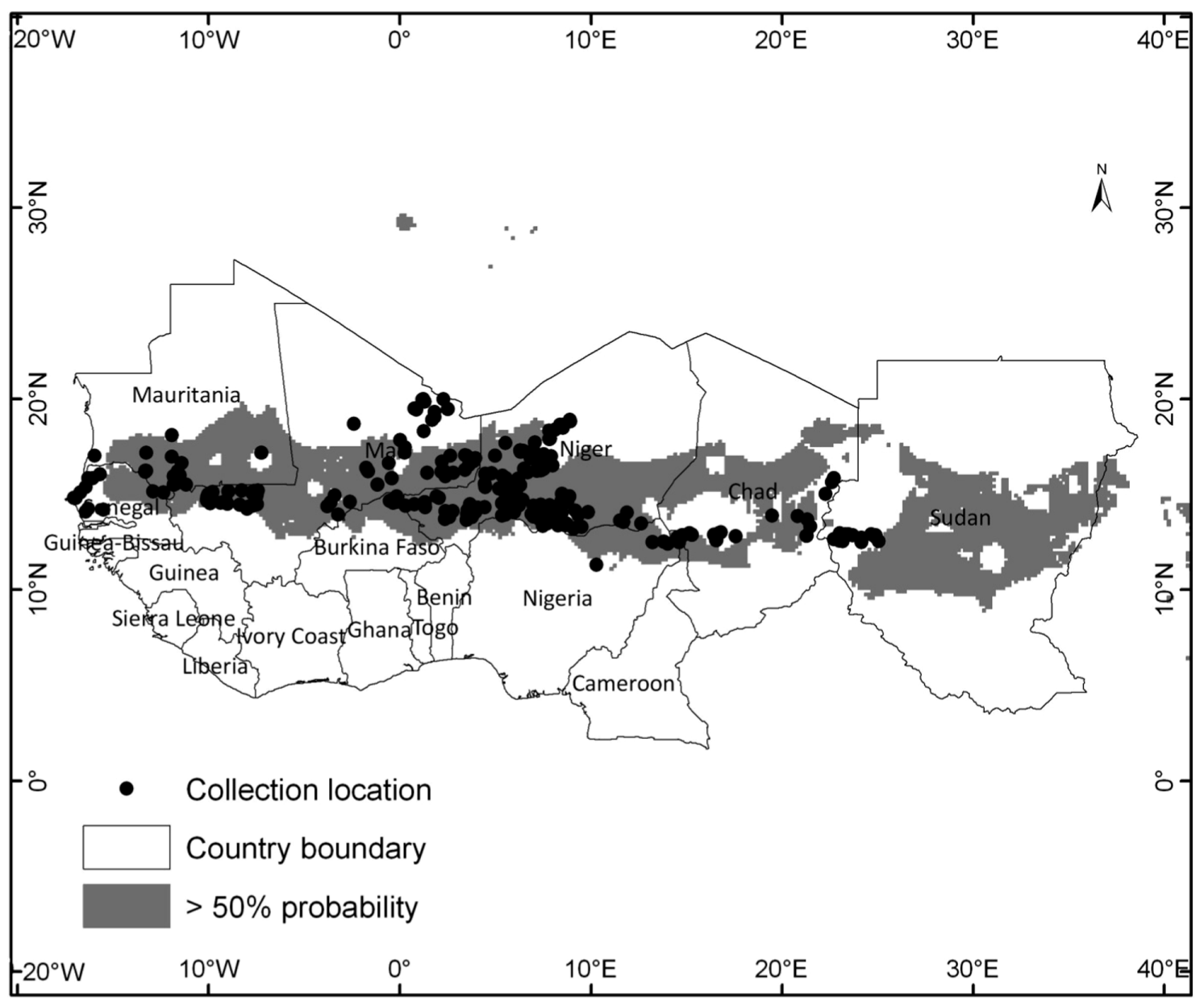

Fig. 2. Geographical distribution of Pennisetum glaucum subsp. monodii germplasm assembled at the ICRISAT genebank and the high-probability $(>50 \%)$ areas of its occurrence (shaded area).

tillers per plant suggests that the selection for total tillers will result in selection for productive tillers. In future characterization and evaluation of germplasm, an easily and early measurable trait (total tillers per plant) may be used. Similarly, selection for leaf length will reflect the selection for leaf width. The highly significant correlation between plant height, stem thickness, leaf length and leaf width indicates that the selection for any of these traits will result in the selection for other traits in P. glaucum subsp. monodii.

Bramel-Cox et al. (1986) reported the high potential of $P$. glaucum subsp. monodii for increasing the growth rate in pearl millet. Hanna (1997) showed that hybrids with cytoplasms from different $P$. glaucum subsp. monodii accessions produced up to $17 \%$ more dry matter than the commercial check Tifleaf 1 because of either cytoplasmic and/or cytoplasmic-nuclear effects. Rai and Rao (1996) reported IP 21651 and IP 21652 from Mauritania, IP 21662 from Senegal, IP 21705 from Chad, and IP 21731 and IP 21736 from Sudan to be the restorers for $\mathrm{A}_{5}$ cytoplasm.
Genetic resistance to rust (Puccinia substriata Ellis \& Barth; var. indica Ramchar and Cummins), pyricularia leaf spot (Pyricularia grisea (Cke) Sarc.) and smut (Moesziomyces penicillariae (Bref.) Vanky) (Wilson and Hanna, 1992) has been identified in P. glaucum subsp. monodii accessions and incorporated into inbred lines to develop commercial pearl millet forage (Hanna et al., 1988) and grain (Hanna, 1993) hybrids. Wilson et al. (2004) reported P. glaucum subsp. monodii to be a source of Striga (Striga hermonthica) resistance. Singh and Navi (2000) screened about 273 accessions of $P$. glaucum subsp. monodii for downy mildew resistance and reported 11 accessions to be free from downy mildew with $0 \%$ downy mildew incidence. Singh et al. (1997) reported IP 21973 from India, IP 21978 from Niger, and IP 22024, IP 22026, IP 22031, IP 22033, IP 22037, IP 22041, IP 22043, IP 22055 and IP 22056 from Mali to be free from downy mildew. Accessions IP 22024 and IP 22026, which were found to be downy mildew resistant and also produced 174 total and 110 productive tillers, 
may be exploited to develop downy mildew-resistant pearl millet fodder varieties. When compared with other countries, in Mali, a maximum of $19 \%$ accessions were found to be disease free (Singh and Navi, 2000). Downy mildew-resistant genes in these accessions are valuable additions to the existing sources of cultivated pearl millet. In the present study, among all the countries, Mali with a maximum of 158 districts was identified as the major geographical gap in the collection. Therefore, exploration for $P$. glaucum subsp. monodii germplasm in Mali may result in promising sources of downy mildew resistance as well as high fodder yield.

Natural diversity inherent in CWR populations is a finite world resource that is being eroded or lost, in part, by careless, unsustainable human practices (Upadhyaya and Gowda, 2009). This loss of CWR diversity can occur at both taxonomic (species) and genetic levels. Therefore, critical assessment of existing collections, particularly those of wild relatives, for diversity and identification of geographical and taxonomic gaps are necessary. Launching germplasm collection missions in unexplored and underexplored areas is essential to safely conserve the variability available in CWRs. Geographical distribution of wild species is often scanty and patchy and makes it difficult to assess and map its occurrence in nature. The collection strategy for wild relatives involves difficulties in the identification of geographical distribution of species, precise location, time of maturity, etc., the information for which needs to be gathered from different flora, herbaria, catalogues and literature and through correspondence. Although the information available is scanty and old, several reports indicated the occurrence of pearl millet wild relatives in East and Southern African countries (Appa Rao, 1979; Ramanatha Rao, 1981; Remanandan and Mengesha, 1981; Appa Rao et al., 1991). Upadhyaya et al. (2012) reported the occurrence of $P$. glaucum subsp. monodii in Sudan. The use of GIS tools to analyse passport data and corresponding climate data to map the potential distribution of a species is a powerful method that can assist germplasm collectors and genebank managers. The probability map generated using FloraMap in the present study matched quite closely to the origin of pearl millet, supporting the prediction of $P$. glaucum subsp. monodii occurrence in the primary centre of diversity for pearl millet (Brunken et al., 1977; Appa Rao and de Wet, 1999). It is important to go through different flora and fauna, catalogues and literature for the distribution of species and its maturity before embarking on an actual germplasm collection mission. It is also required to have the overall knowledge of wild relatives of crop to make the collection mission a success.
Being the primary centre of diversity for pearl millet, Sahelian region could be a good source of many Pennisetum species (Clayton, 1972). Of more than 140 species reported in the genus Pennisetum, only 16 species were assembled from the primary centre of diversity for pearl millet (Hanna, 1987). P. glaucum subsp. monodii is capable of hybridizing with the cultivated crop to produce weedy fertile offspring that mimic the cultivated crop in their vegetative and floral morphologies. The intermediate weedy form is not reproductively isolated from pearl millet and occupies a distinctive niche within the primary gene pool. The weedy forms involving pearl millet and monodii are known as P. glaucum subsp. stenostachyum (Klotzsch) Brunken. These spontaneous weedy mimetic forms are called Shibras in the Hausa language spoken in Niger and Nigeria and as N'Douls in the Ouolof language spoken in Senegal. It is difficult to recognize weedy forms till about maturity, by which time they disperse their pollen. Shibras, which mature early by at least 3-4 weeks compared with the cultivated millet, can be a good source of early maturity. In view of large gaps, it is suggested that collection missions be launched in SubSaharan Africa, particularly in countries under study, exclusively for Pennisetum species to fill taxonomic and geographical gaps in the world collection of pearl millet wild relative germplasm. The gaps identified in the present study may be prioritized depending on the threat to the diversity. In view of its importance as a source of high dry matter yield, disease resistance, diversified cytoplasm and low intensity of collection in the primary centre of diversity, particularly in countries under study, suggest the need for launching germplasm collection missions, exclusively for $P$. glaucum subsp. monodii germplasm.

\section{Supplementary material}

To view supplementary material for this article, please visit http://dx.doi.org/10.1017/S1479262113000555

\section{Acknowledgements}

The authors thank all the former and present staff of Genetic Resources Unit (GRU), ICRISAT, for their contribution to the collection, assembly and conservation of pearl millet genetic resources. They also thank Senthil Ramachandran, Scientific Officer, and D Bapa Rao, G Dasaratha Rao and G Ram Reddy, Research Technicians, Genetic Resources Unit, ICRISAT, India, for their help in recording observations and documenting data for this study. 


\section{References}

Appa Rao S (1979) Germplasm collecting mission in Malawi. Genetic Resources Progress Report 2. Patancheru: Genetic Resources Unit, International Crops Research Institute for the Semi-Arid Tropics (ICRISAT).

Appa Rao S and de Wet JMJ (1999) Taxonomy and evolution. In: Khairwal IS, Rai KN, Andrews DJ and Harinarayana G (eds) Pearl Millet Breeding. New Delhi: Oxford \& IBH Publishing Co. Pvt. Ltd., pp. 29-47.

Appa Rao S, Monyo ES, House LR, Mengesha MH and Negumbo I (1991) Germplasm collection mission to Namibia. Genetic Resources Progress Report 67. Patancheru: Genetic Resources Unit, International Crops Research Institute for the Semi-Arid Tropics (ICRISAT).

Bramel-Cox P, Andrews DJ and Frey KJ (1986) Exotic germplasm for improving grain yield and growth rate in pearl millet. Crop Science 26: 687-693.

Brunken JN, de Wet JMJ and Harlan JR (1977) The morphology and domestication of pearl millet. Economic Botany 31: $163-174$.

Clayton WD (1972) Graminae. In: Hutchinson J, Dalziel JM (eds) and Hepper FN (rev) Flora of West Tropical Africa, 2nd edn., vol III, Part 2. London: Crown agents for Overseas Governments and Administration, pp. 349-512.

Hanna WW (1987) Utilization of wild relatives of pearl millet. In: Witcombe JR and Beckerman SR (eds) Proceedings of International Pearl Millet Workshop, 7-11 April 1986. ICRISAT Center, India. Patancheru: ICRISAT, pp. 33-42.

Hanna WW (1993) Registration of pearl millet parental lines Tift 8677 and A1/B1 Tift 90D $\mathrm{D}_{2}$. Crop Science 33: 1119.

Hanna WW (1997) Influence of cytoplasms from a wild grassy subspecies on dry matter yields in pearl millet. Crop Science 37: 614-616.

Hanna WW, Wells HD, Burton GW, Hill GM and Monson WG (1988) Registration of Tifleaf 2 pearl millet. Crop Science 28: 1023.

IBPGR and ICRISAT (1993) Descriptors for pearl millet [Pennisetum glaucum (L.) R.Br.]. Rome/Patancheru: IBPGR/ICRISAT, p. 43.

Jones PG and Gladkov A (1999) FloraMap: a computer tool for predicting the distribution of plants and other organisms in the wild. version 1. In: Jones AnnieL (ed.) CIAT, CD-ROM eries. Cali: Centro Internacional de Agricultura Tropical.

Keuls M (1952) The use of the studentized range in connection with an analysis of variance. Euphytica 1: 112-122.

Levene H (1960) Robust tests for equality of variances. In: Olkin I (ed.) Contributions to Probability and Statistics: Essays in Honor of Harold Hotelling. Stanford: Stanford University Press, pp. 278-292.

Mariac C, Luong V, Kapran I, Mamadou A, Sagnard F, Deu M, Chantereau J, Gerard B, Jupiter Ndjeunga, Bezançon G, Pham J and Vigouroux Y (2006) Diversity of wild and cultivated pearl millet accessions (Pennisetum glaucum [L.] R. Br.) in Niger assessed by microsatellite markers. Theoretical and Applied Genetics 114: 49-58.
MS Encarta ${ }^{\mathrm{R}}$ Interactive World Atlas (2000) 1995-1999 Microsoft Corporation. Redmond, WA: One Microsoft way, pp. 98052-106399.

Newman D (1939) The distribution of range in samples from a normal population expressed in terms of an independent estimate of standard deviation. Biometrika 31: 20-30.

Patterson HD and Thompson R (1971) Recovery of inter-block information when block sizes are unequal. Biometrica 58 : $545-554$.

Rai KN and Rao AS (1996) A new CMS system and its restorers in pearl millet. Abstracts. 2nd International Crop Science Congress, 17-23 November.

Ramanatha Rao V (1981) Germplasm collection mission to Mozambique. Genetic Resources Progress Report 35. Patancheru: Genetic Resources Unit, International Crops Research Institute for the Semi-Arid Tropics (ICRISAT).

Remanandan P and Mengesha Melak H (1981) Pigeonpea germplasm collection mission in Tanzania. Genetic Resources Progress Report 38. Patancheru: Genetic Resources Unit, International Crops Research Institute for the Semi-Arid Tropics (ICRISAT).

SAS Institute (2010) SAS User's Guide: Statistics. Version 9.1.3. Cary, NC: SAS Institute.

Shannon CE and Weaver W (1949) The Mathematical Theory of Communication. Urbana, IL: University of Illinois Press.

Singh SD and Navi SS (2000) Genetic resistance to pearl millet downy mildew II. Resistance in wild relatives. Journal of Mycology and Plant Pathology 30: 167-171.

Singh SD, JP Wilson, SS Navi, BS Talukdar, DE Hess and KN Reddy (1997) Screening techniques and sources of resistance to downy mildew and rust in pearl millet. Information Bulletin No. 48. Patancheru: International Crops Research Institute for the Semi-Arid Tropics, 36 pp. ISBN 92-9066-352-9.

Snedecor GW and Cochran WG (1980) Statistical Methods. 7 th edn. Ames, IA: Iowa State University Press.

Upadhyaya HD and Gowda CLL (2009) Managing and enhancing the use of germplasm - strategies and methodologies. Technical Manual No. 10. Patancheru: International Crops Research Institute for the Semi-Arid Tropics.

Upadhyaya HD, Reddy KN, Irshad Ahmed M and Gowda CLL (2012) Identification of gaps in pearl millet germplasm from East and Southern Africa conserved at the ICRISAT genebank. Plant Genetic Resources: Characterization and Utilization 10: 202-213.

Ward JH (1963) Hierarchical grouping to optimize an objective function. Journal of the American Statistical Association 58: $236-244$.

Wilson JP and Hanna WW (1992) Effects of gene and cytoplasm substitutions in pearl millet on leaf blight epidemics and infection by Pyricularia grisea. Phytopathology 82: $839-842$.

Wilson JP, Hess DE, Hanna WW, Kumar KA and Gupta SC (2004) Pennisetum glaucum subsp. monodii accessions with striga resistance. Crop Protection 23: 865-870. 